\title{
Sezgisel Bulanık Mantık ve Entropi Tabanlı Çok Kriterli Karar Verme Yöntemiyle Finansal Performans Analizi: BİST'de İşlem Gören Enerji Şirketleri Üzerine Bir Uygulama ${ }^{1}$
}

\author{
Reşat KARCIOĞLU², Selçuk YALÇIN ${ }^{3}$ ve Ömer Faruk GÜLTEKİN ${ }^{4}$ \\ Öz \\ Teknolojinin hızla gelişmesi sonucunda enerjiye olan ihtiyaç her geçen gün artmaktadır. Artan enerji ihtiyacı ülkelerin \\ ekonomik kalkınma süreçlerinde enerji sektörünün hayati bir öneme sahip olmasına neden olmuştur. Bu çalışmada \\ BIST’te işlem gören 8 enerji şirketinin finansal performansı sezgisel bulanık mantık ve çok kriterli karar verme \\ teknikleri kullanılarak incelenmiştir. Çalışmada 8 enerji şirketinin 2013-2017 yıllarına ait gerçek verileri kullanılmışır. \\ Karar sürecinde; büyüme, faaliyet, kaldıraç, karlılık ve likidite olmak üzere 5 ana kriter ile 13 alt kriter kullanılmıstır. \\ Yapılan analiz sonucunda 8 enerji şirketi arasında en iyi performansı Odaş Elektrik A.Ş gösterirken en kötü \\ performansı ise Ayen Elektrik A.Ş göstermiştir.
}

Anabtar Kelimeler: Finansal Performans, Sezgisel Bulanık Mantık, Çok Kriterli Karar Verme

Financial Performance Analysis Using Intuitionistic Fuzzy Logic and Entropy Based Multi - Criteria Decision Making Method: An Application on Energy Companies Traded In BIST

\begin{abstract}
As a result of the rapid development of technology, the need for energy increases day by day. Increased energy demand caused the energy sector to have a vital importance in the economic development processes of countries. In this study, the financial performance of 8 energy companies traded in BIST are analyzed using intuitionistic fuzzy logic and multi-criteria decision making techniques. In the study, the data, the real data of the 8 energy companies between 2013 and 2017 were used. In decision process, 5 main criteria and 13 sub-criteria were used as growth, activity, leverage, profitability and liquidity. As a result of the analysis, Odaş Elektrik A.Ş showed the best performance among 8 energy companies, while Ayen Elektrik A.Ş showed the worst performance.
\end{abstract}

Key Words: Financial Performance, Intuitionistic Fuzzy Logic, Multi-Criteria Decision Making

\section{Atıf İçin / Please Cite As:}

Karcıoğlu, R., Yalçın, S. ve Gültekin, Ö. F. (2020). Sezgisel bulanık mantık ve entropi tabanlı çok kriterli karar verme yöntemiyle finansal performans analizi: BİST’de işlem gören enerji şirketleri üzerine bir uygulama. Manas Sosyal Arastrumalar Dergisi, 9(1), 360-372.

Geliş Tarihi / Received Date: 04.03.2019

Kabul Tarihi / Accepted Date: 26.06.2019

\footnotetext{
${ }^{1}$ Bu çalışma 3-5 Mayıs 2018 tarihinde gerçekleştirilen Uluslararası Uygulamalı İşletme Yönetim ve Ekonomi Araştırmaları Sempozyumu'nda özet olarak sunulan "Sezgisel Bulanık Mantık Yöntemiyle Enerji Şirketlerinin Finansal Performans Analizi ” isimli çalışmanın genişletilmiş ve revize edilmiş halidir.

2 Prof. Dr. - Atatürk Üniversitesi İktisadi ve İdari Bilimler Fakültesi, rkarci@atauni.edu.tr - ORCID : 0000-0002-0903-3816

3 Arş. Gör. - Bayburt Üniversitesi İktisadi ve İdari Bilimler Fakültesi, syalcin@bayburt.edu.tr - ORCID : 0000-0002-0997-7614

4 Arş. Gör. - Bayburt Üniversitesi İktisadi ve İdari Bilimler Fakültesi, ofgultekin@bayburt.edu.tr - ORCID: 0000-0002-4832-4683
} 


\section{Giriş}

Küreselleşme süreciyle beraber sınırların ortadan kalkması şirketlerin artan rekabet koşullarıyla karşı karşıya kalmasına yol açmıştır. Bu rekabet şartlarına uyum sağlayabilen şirketler yaşamlarını sürdürebilmekte, uyum sağlayamayan şirketler ise önce pazar paylarını ve karlılıklarını kaybetmekte, sonrasında ise varlıklarını sürdürememektedir. Şirketler rekabette başarılı olabilmek için ellerindeki kaynakları doğru ve etkili bir şekilde kullanmalı, performanslarını mümkün olduğunca yüksek seviyede tutmalıdırlar. Performans kavramı; işletmelerin amaçlarına ulaşma düzeyidir. Bir işletmenin başarısını devam ettirebilmesi ve bu başarıda süreklilik arz edebilmesi ise performans ölçümü ile cevabını bulmaktadir (Karaman, 2009).

Finansal performansını üst düzeyde tutabilen şirketler, ulusal ve uluslararası piyasalarda rekabet avantajına sahip olabilmektedir. Rekabet avantajına sahip olan şirketler ise karlılıklarını ve pazar paylarını artırmaktadır. Bu durum doğal olarak şirketin başarılı olmasını ve varlığını sürdürmesini sağlamaktadır. Şirketlerin varlıklarını sürdürebilmeleri şirket adına çok önemli bir süreçtir ve bu sürecin devamını sağlayabilmek adına birçok etmen bulunmaktadır. Şirketlerin varlıklarını sürdürebilmeleri için en önemli etmenlerden biri finansal performanslarının ölçülmesi, analiz edilmesi ve en doğru şekilde yorumlanabilmesidir.

Finansal performans ölçümünde şirketin finansal verilerine (bilanço, kar zarar tablolar) farklı açlardan yaklaşılarak değişik sorulara cevaplar aranır. Şirketin finansal performansına işaret eden karlılık, satışların hacmi, kaynakların verimli (ve karlı) kullanılma becerisi, borçluluk oranı, borç ödeyebilme yeteneği, firmanın piyasadaki durumu gibi göstergeler farklı oranlar yardımıyla incelenmektedir. (Aydın, 2009)

İşletmelerin finansal performansları, hedeflenen ve ulaşılan durumu görebilmek adına alternatif yöntemlerle hesaplanmaktadır. Bu hesaplamayı yaparken birçok kriter göz önüne alınmalı ve buna göre değerlendirme yapılmalıdır. Bu amaçla performans analizlerinde, farklı kriterleri göz önüne alarak değerlendirme yapmaya olanak sağlayan çok kriterli karar verme yöntemleri kullanmak oldukça yaygin bir yöntemdir.

Yaşadığımız evren belirsiz, tutarsız ve tam olmayan bilgilerle doludur. Klasik yöntemler ile bu karmaşık bilginin işlenmesi kolay değildir. Bu nedenle gerçek hayattaki bu karmaşık ve belirsizlik içeren durumları ifade etmek için Zadeh (1965) bulanık kümeler teorisini tanımlamıştır. Zadeh (1965) belirsizlik durumlarında bulanık mantığın klasik mantığa göre insanın zihinsel çalısma süreçlerini daha doğru yansıttığını belirtmiştir. Bulanık mantığın belirsizlik içeren durumları modellemedeki başarısı ve insan düşünce ve karar sistemine yatkınlığı, bulanık mantığın finans alanında kullanımını mümkün kılmaktadır.

Özellikle son ylllarda çok kriterli karar verme yöntemleri, alternatifler arasından en iyisini seçme, alternatifleri sıralama gibi karar verme problemlerinde bulanık mantık ile iç içe yaygın olarak kullanılmaya başlanmıştır. Bunun beraberinde bulanık mantı̆̆ın finans alanında kullanımı oldukça yeni olmasına rağmen her geçen gün yapılan çalışma sayısı artmaktadır.

Bu çalısmada Zadeh'in bulanık kümelerinin bir genellemesi olan sezgisel bulanık kümeler (Atanassov, 1986) kullanılarak, entropi tabanlı çok kriterli bir karar verme metodu geliştirilmiştir. Bu yöntem bize alternatifleri belirlenen kriterlere göre sıralama konusunda daha esnek ve daha doğru şekilde bir sıralama yapma imkanı sağlamaktadır. Çalışmada; kriter ağırlıklarının tamamen bilinmediği bir karar sürecinde, öncelikle BİST'de işlem gören 8 enerji şirketinin 2013-2017 yillarına ait verileri incelenmiş ve alternatiflere ait bu veriler önce dilsel terimlerle değerlendirilmiş ardından bu dilsel değerlendirme sezgisel bulanık sayılarla ifade edilmiştir. Daha sonra entropy kavramı kullanılarak kriterlerin ağırlık bilgisi hesaplanmış ve son olarak ise elde edilen bütün veriler kullanılarak alternatifler sıralanmıştır.

\section{Literatür}

Wang \& Hsu (2004) Tayvan menkul kıymetler borsasında işlem gören 10 işletmenin stok devir hızı, net kar marji, hisse başına getiri ve cari oran verilerini kullanarak yaptıkları analizde çok kriterli karar verme yöntemlerinden biri olan TOPSIS yöntemini kullanmışlardır. Yazarlar yatırımcıların karar verme ve yatırım stratejilerinin belirlenmesi süreçlerinde TOPSİS yönteminin faydalı olabileceğini belirtilmişlerdir.

Bo \& Haidong (2008) Çin borsasında işlem gören 112 işletmenin 11 tane finansal oranını kullanarak yaptıkları çalş̧mada, TOPSİS yönteminin finansal kriz dönemlerinde işletmelerde erken uyarı sistemi olarak kullanılabileceğini belirtmişlerdir. 
Dumanoğlu ve Ergül (2010) yaptıkları çalışmada İstanbul Menkul Kıymetler Borsası'nda işlem gören 11 teknoloji şirketinin finansal performansını analiz etmişlerdir. Yazarlar çalışmada teknoloji şirketlerinin 2006-2009 dönemine ait mali tablolarını kullanarak her bir şirket için finansal oranları hesaplamıs, daha sonra hesaplanan bu oranları çok kriterli karar verme yöntemlerinden biri olan TOPSİS yöntemi ile tek bir puana dönüştürerek sıralama yapmışlardır. Yapılan sıralama sonucunda finansal performans açısından en başarılı bilişim şirketinin Arena Bilgisayar Sanayi ve Ticaret A.Ş (ARENA), en başarısız biliş̧im şirketinin ise Escort Computer Elektronik Sanayi ve Ticaret A.Ş (ESCOM) olduğunu belirtmişlerdir.

Atmaca (2012) yaptığı çalışmada İMKB'de işlem gören spor şirketleri; Fenerbahçe (FB), Galatasaray (GS), Beşiktaş (BJK) ve Trabzonspor (TS) Sportif A.Ş.'nin finansal performanslarını analiz etmiştir. Çalışmada spor şirketlerinin 2003-2010 dönemine ait finansal tablolarından elde edilen 16 tane finansal oranı kullanılmıştır. TOPSíS yöntemi kullanılarak yapılan analizde 2003-2010 yıllarının genelinde Fenerbahçe Sportif Hizmetler Sanayi ve Ticaret A.Ş.'nin diğer rakiplerine göre daha iyi bir performans ortaya koyduğu tespit edilmiştir.

Doğan (2013), Türkiye'de bankacılık sektöründe faaliyette bulunan katılım bankalarının ve geleneksel bankaların finansal performanslarını karşılaşıırmışıı. Bankaların 2005-2011 dönemine ait veriler kullanılarak yapılan analizde, geleneksel bankaların katılım bankalarına göre likiditesinin, borç ödeme gücünün ve sermaye yeterliliğinin daha yüksek, riskliliğinin ise daha düşük olduğu belirlenmiştir. Ayrıca katılım bankaları ve geleneksel bankaların kârlılıkları arasında istatistiksel olarak anlamlı bir farklılık olmadığı tespit edilmiştir.

Ergül (2014), yaptığ1 çalışmada Borsa İstanbul (BİST) turizm sektöründe işlem gören şirketlerin finansal performansının belirlenmesinde çok kriterli karar verme tekniklerinden ELECTRE-III ve TOPSIS yöntemlerinin başarılı yöntemler olup olmadığını araştırmıştır. BİST'de işlem gören turizm şirketlerinin 2005-2012 yıllarına ait mali tabloları kullanılan çalışmada ELECTRE-III ve TOPSIS yöntemiyle yapılan analiz sonuçları ile temel analiz sonucunda elde edilen sonuçların birbiriyle tutarlı̆̆ olduğu ve bu yöntemlerin çok kriterli karar verme süreçlerinde başarıll yöntemler olduğu belirtilmiştir.

Akbulut ve Rençber (2015), BİST’te işlem gören imalat sektöründeki işletmelerin finansal performansları ile borsa performansları arasında ilişki olup olmadığını araştırmışlardır. Çalışmada imalat sektöründeki 32 şirketin 2010-2012 dönemine ait finansal verileri TOPSíS yöntemiyle analiz edilmiș ve bu analiz sonucunda her bir şirkete ait finansal performans skorları elde edilmiştir. Elde edilen bu skorlar şirketlerin 2010-2012 dönemine ait borsa performanslarıyla karşılaştırılmış ve şirketlerin finansal performansları ile borsa performansları arasında anlamlı bir ilişki olmadığı sonucuna ulaşılmıştır.

Shaverdi, Ramezani, Tahmasebi \& Rostamy (2016), çalışmalarında Tahran Borsası'nda işlem gören 7 petrokimya şirketini rekabet gücü açısından sıralamak için Bulanık TOPSíS yöntemini kullanmışlardır. Çalışmada 2003-2013 yılları arasındaki mali tablolardan elde edilen 15 finansal oran kullanılmış olup analiz sonucunda 7 şirket rekabet gücü açısından sıralanmış fakat ağırlık oranlarının birbirine çok yakın olduğu tespit edilmiştir.

Eyüboğlu ve Çelik (2016), Türk enerji şirketlerinin finansal performansını Bulanık Analitik Hiyerarşi ve Bulanık Topsis yöntemiyle analiz ettikleri çalıssmada 5 ana 15 alt kriter kullanmışlardır. Yazarlar ilk olarak 5 ana kriterin daha sonra da her bir alt kriterin ağırlıklarını bulanık mantık yardımıyla hesaplamışlardır. Kriter ağıllıkları belirlendikten sonra TOPSİS yöntemiyle yapılan sıralama sonucunda en iyi performansı Avrasya Petrol ve Turistik Tesisler Yatırımlar Anonim Şirketi’nin (AVTUR), en kötü performansı ise Zorlu Enerji Anonim Şirketi'nin (ZOREN) gösterdiği belirtilmiştir.

Tezergil (2016), Türk bankacılık sektöründe faaliyet gösteren 28 bankanın 2009-2013 yıllarına ait bilançolarından elde edilen finansal oranları kullandığı çalışmada çok kriterli karar verme yöntemlerinden biri olan VIKOR yöntemini kullanmıştır. Yaptı̆̆1 analiz sonucunda 2009 ve 2010 yıllında en iyi performans1 Akbank'ın, 2011 ve 2012 yıllarında Ziraat bankasının, 2013 yılında ise Citibank'ın gösterdiğini tespit etmiştir.

Kula vd. (2016) BİST’de işlem gören 7 sigorta şirketi ve 1 bireysel emeklilik şirketinin 2013 yllina ait verilerini kullanarak finansal performans analizi yapmışlardır. Yazarlar çalısmada yöntem olarak çok kriterli karar verme yöntemlerinden "Gri İlişkisel Analiz" yöntemini kullanmışlardır. Yapılan analizler sonucunda en iyi performansı Ak Sigorta şirketinin, en kötü performansı ise Aviva Sigorta şirketinin gösterdiğini belirtmişlerdir. 
Ceyhan ve Demirci (2017), BİST'de işlem gören 6 finansal kiralama şirketinin, çok kriterli karar verme yöntemlerinden Multımoora yöntemini kullanarak finansal performans analizini yaptıklanı çalışmada en iyi performansı Yapı Kredi Finansal Kiralama Anonim Ortaklığ1 şirketinin, en kötü performansı ise Şeker Finansal Kiralama Anonim Şirketi’nin gösterdiğini belirtmişlerdir.

Orçun ve Eren (2017) yaptıkları çalşmada Borsa İstanbul'da (BIST) işlem gören teknoloji şirketlerinin finansal performansını TOPSIS yöntemi ile analiz etmişlerdir. 2010-2015 yılları arasındaki dönemi kapsayan çalışmada, performans açısından en başarılı şirketler sırasıyla, ASELS, LINK, ARMDA, LINK, INDES ve DGATE şeklinde belirlenmiştir. Ayrıca, şirketlerin 2010-2015 yılları dönemindeki borsa getirileri ile analiz sonucunda elde edilen finansal performans sıralamaları arasında anlamlı bir ilişki tespit edilememiştir.

Yıldırım, Altan ve Gemici (2018), yaptıkları çalışmada Borsa İstanbul (BIST) Kurumsal Yönetim Endeksinde (XKURY) işlem gören, 5 adet Gıda ve İçecek şirketinin 2013-2016 dönemindeki kurumsal yönetim notları ve finansal performansları arasındaki ilişskiyi Entropi ağırlıklandırmalı TOPSIS yöntemiyle incelemişlerdir. Yapılan analiz sonucunda şirketlerin kurumsal yönetim notlanı ile finansal performans notları arasında sürekli ve anlamlı bir ilişkinin bulunmadığını tespit etmişlerdir.

Başdeğirmen ve Işıldak (2018), ulaştırma sektöründe faaliyet gösteren sekiz işletmenin finansal performansını Gri İlişkisel Analiz yöntemi ile analiz etmişlerdir. Yazarlar çalışmanın ilk bölümünde değerlendirme kriterlerinin eşit önem derecesine sahip olduğu, ikinci bölümünde ise uzman görüşünden yararlanılarak farklı kriter ağırlıklarına sahip olduğu modeller kullanmışlardır. Çalışmanın sonucunda sektörde yer alan işletmelerin finansal performansını belirlemede; çalışan sayısı, özsermaye ve toplam aktifler gibi kriterlerin daha yüksek öneme sahip olduğu, özellikle ihracat ve vergi öncesi kâr kriterlerinin daha düşük öneme sahip olduğu belirlenmiştir.

\section{Yöntem}

Bu bölümde bulanık küme, sezgisel bulanık küme, entropi kavramları açıklanmış ve kullanılan sezgisel bulanık mantık ve entropi tabanlı çok kriterli karar verme yönteminin adımları açıklanmışır.

\section{Bulanık Küme}

Bulanık mantık kavramını ilk öne süren kişi Lütfü Zadeh (1965) olmuştur. Zadeh birçok kavramın dilsel olarak geleneksel matematiğe göre daha iyi belirlenebildiğini ve bulanık mantığın ve onun bulanık kümelerdeki ifadelerinin gerçek hayatın daha iyi modelini oluşturduğunu göstermiştir (Yıldız ve Kişoğlu: 2014, 14). Klasik küme kavramında karakteristik fonksiyon ile bir eleman bir kümenin ya elemanıdır ya da elemanı değildir. Fakat bulanık küme kavramında bir elmanın bir kümeye ait olup olmama durumu, her bir nesneye $[0,1]$ aralığında bir üyelik derecesi atayan bir üyelik fonksiyonuyla tanımlanmaktadır (Zadeh: 1965, 338).

Tanım $1: X$ boş olmayan bir küme ve $x \in X$ olsun. $\mathrm{O}$ halde $\mu_{A}(x): X \rightarrow[0,1]$ fonksiyonu için $\mu_{A}(x), x$ elemanının üyelik derecesini göstermek üzere $X$ de bir bulanık A kümesi;

$A=\left\{\left(x, \mu_{A}(x)\right): x \in X\right\}$ şeklinde ifade edilir. Aslında, her üyelik fonksiyonu bir klasik evrensel kümenin elemanlarını $[0,1]$ aralığındaki bir sayıya karşılık getiren bir fonksiyondur.

\section{Sezgisel Bulanık Küme}

Bulanık A kümesinde bir elemanın kümeye ait olma derecesi $\mu_{A}$ iken ait olmama derecesi ise 1- $\mu_{A}$ 'dır. Dolayısıyla ait olma ve ait olmama derecelerinin toplamı 1'e eşittir. Fakat bu durum karşılaşılan bazı problemlerdeki belirsizlik durumunu açıklamada yetersiz kalmaktadır. Bu nedenle Atanassov (1986) bulanık küme teorisinin genelleştirilmiş hali olan sezgisel bulanık küme teorisini önermiştir.

Tanım $2: X$ boş olmayan bir küme ve $x \in X$ olsun. O halde $\mu_{S}(x): X \rightarrow[0,1]$ ve $\vartheta_{S}: X \rightarrow[0,1]$ iki fonksiyon için;

$$
S=\left\{\left(x, \mu_{S}(x), \vartheta_{S}(x)\right): x \in X\right\}
$$

kümesine sezgisel bulanık küme denir. Burada, $\mu_{S}(x), x$ elemanının $S$ kümesine ait olma derecesini gösterirken $\vartheta_{S}(x)$ de $x$ elemanının $S$ kümesine ait olmama derecesini gösterir. Bir sezgisel kümede tereddüt durumu; $\pi_{S}(x)=1-\left(\mu_{S}(x)+\vartheta_{S}(x)\right)$ şeklinde tanımlanır. Dolayısıyla,

$$
0 \leq \mu_{S}(x)+\vartheta_{S}(x) \leq 1
$$


eşitliği vardır. Bir sezgisel bulanık küme, sezgisel bulanık sayılardan oluşur ve bir sezgisel bulanık $\alpha$ sayısı kısaca $\alpha=\left(\mu_{a}, \vartheta_{a}\right)$ ile gösterilir.

Sezgisel bulanık sayıları sıralamak için skor fonksiyonu (Chen ve Tan, 1994) kullanılabilir. $\alpha=$ $\left(\mu_{a}, \vartheta_{a}\right)$ sezgisel bulanık sayının skor değeri $\operatorname{Skor}(\alpha)=\mu_{a}-\vartheta_{a}$ ile hesaplanır. Skor değeri büyük olan sezgisel bulanık sayı daha büyüktür.

Tereddüt derecesi $\left(\pi_{A}(x)\right)$ bir x elemanının A kümesine ait olup olmamasındaki tereddütlük düzeyini belirtmektedir. Eğer tereddüt derecesi büyükse o elemanın o kümeye ait olma durumu göreceli olarak daha belirsiz, tereddüt derecesi küçükse o kümeye ait olma durumu göreceli olarak daha belirgindir.

Karar verme metotlarında bilginin toplanması ve toplanan bilgi ile sonuçların elde edilmesi temel teşkil etmektedir. Sezgisel bulanık verilerin toplanması yani ortalama değerlerinin bulunması için Xu (2007) tarafindan bir aritmetik ortalama operatörü geliştirilmiştir

Tanım $3: \alpha_{i}=\left(\mu_{a_{i}}, \vartheta_{a_{i}}\right)(i=1,2, \ldots, n) \mathrm{n}$ tane sezgisel bulanık sayı olsun. $w=\left(w_{1}, w_{2}, \ldots, w_{n}\right)$ verilen sayıların ağırlık vektörü olmak üzere aritmetik ortalama;

$$
A O\left(\alpha_{1}, \alpha_{2}, \ldots, \alpha_{n}\right)=\left(1-\prod_{i=1}^{n}\left(1-\mu_{i}\right)^{w i}, \quad \prod_{i=1}^{n} \vartheta_{i}^{w_{i}}\right)
$$

şeklinde tanımlanır.

Yukarıda verilen tanımlara göre sezgisel bulanık mantık kullanmak, şirketlerin finansal performansını belirlemede esnek bir karar süreci sağlamaktadır. Bu çalışmada şirketlerin finansal performansını belirlemek için önerilen yöntem Das vd. (2014) takip edilerek aşağıda belirtilen adımlardan oluşturulmuştur. Bu çalışmada; $A=\left\{A_{1}, A_{2}, \ldots, A_{m}\right\}$ alternatiflerin kümesini, $C=\left\{C_{1}, C_{2}, \ldots, C_{n}\right\}$ ise kriterlerin kümesini oluşturmaktadır.

\section{Adım : " $m$ " Alternatifli " $n$ " Kriterli Karar Matrisin Oluşturulması}

Her bir alternatif için veriler toplanır, bu veriler dilsel olarak değerlendirilir ve bu dilsel terimler sezgisel bulanık sayılara dönüştürülerek karar matrisi (D) oluşturulur.

$$
D=\left[\begin{array}{cccc}
x_{11} & x_{12} & \ldots & x_{1 n} \\
x_{21} & x_{22} & \ldots & x_{2 n} \\
\vdots & \vdots & \ddots & \vdots \\
x_{m 1} & x_{m 2} & \ldots & x_{m n}
\end{array}\right]
$$

\section{Adım : Kriter Ağırlıklanının Hesaplanması}

Çok kriterli karar verme problemlerinde her bir kriterin ağırlı̆̆ farklıdır. Bazı kriterler daha çok önem arz edebilirken bazıları ise daha az önemde olabilir. Kriter ağırlıklarının tamamen bilinmediği bir karar sürecinde her bir kriterin ağırlığı aşağıda belirtilen adımlar takip edilerek hesaplanabilir. İlk olarak oluşturulan karar matrisinin (D) entropy matrisi (E) denklem (5) yardımıyla hesaplanır ve aşağıda verilen E matrisi ile gösterilir.

$$
\begin{aligned}
E & =1-\left|\mu_{A}\left(x_{i}\right)-\vartheta_{A}\left(x_{i}\right)\right| \\
E & =\left[\begin{array}{cccc}
e_{11} & e_{12} & \ldots & e_{1 n} \\
e_{21} & e_{22} & \ldots & e_{2 n} \\
\vdots & \vdots & \ddots & \vdots \\
e_{m 1} & e_{m 2} & \ldots & e_{m n}
\end{array}\right]
\end{aligned}
$$

Entropy kelime olarak sistemdeki düzensizliği ifade etmektedir. Bu kavram kullanılarak değerlendirme verilerinin bir bilgi ölçüsü;

$$
K(A)=1-0,5(E(A)+\pi(A))
$$

denklemi ile tanımlanabilir. Bu ölçü bilgisi ile elde edilen ölçü matrisi $K$ ile gösterilir. 


$$
K=\left[\begin{array}{cccc}
k_{11} & k_{12} & \ldots & k_{1 n} \\
k_{21} & k_{22} & \ldots & k_{2 n} \\
\vdots & \vdots & \ddots & \vdots \\
k_{m 1} & k_{m 2} & \ldots & k_{m n}
\end{array}\right]
$$

$K$ matrisi oluşturulduktan sonra, (7) ve (8) denklemleri kullanılarak kriter ağırlıkları $\left(w_{j}\right)$ hesaplanır.

$$
\begin{aligned}
& a_{j}=\sum_{i=1}^{m} k_{i j}, j=1, \ldots, n \\
& w_{j}=\frac{a_{j}}{\sum_{j=1}^{n} a_{j}}
\end{aligned}
$$

\section{Adım : Her Bir Alternatif İçin Ağırlıklandırılmış Ortalama Değetlerin Oluşturulması}

Her bir kriterin ağırlığı hesaplandıktan sonra (9) denklemi kullanılarak ağırlıklandırılmış ortalama değerler $S_{i}=\left(\mu_{i}, \vartheta_{i}\right)$ hesaplanır.

$$
S_{i}=\left(1-\prod_{j=1}^{n}\left(1-\mu_{i j}\right)^{w_{j}}, \quad \prod_{j=1}^{n} \vartheta_{i j}{ }^{w_{j}}\right)=\left(\mu_{i}, \vartheta_{i}\right)
$$

\section{Adim : Alternatiflerin Siralanmas1}

Ağırlıklandırılmış ortalama değerler hesaplandıktan sonra her bir alternatifin aldığı skoru bulmak için Chen ve Tan (1994) tarafindan tanımlanan skor fonksiyonu kullanılabilir. Alternatiflerin skorlar1 hesaplandıktan sonra, en büyük skora sahip alternatif en iyi alternatif anlamına gelmektedir.

$$
\operatorname{Skor}\left(S_{i}\right)=\mu_{i}-\vartheta_{i}, \quad i=1,2, \ldots, m
$$

\section{Karar Verme Yönteminin Bir Uygulaması}

Bu bölümde Borsa İstanbul'da (BİST) işlem gören 8 enerji şirketinin 2013-2017 y1lları arasındaki finansal performansı, sezgisel bulanık mantık ve entropi tabanlı çok kriterli karar verme yöntemiyle analiz edilmiştir. Çalışmada 8 enerji şirketinin 2013-2017 yıllarına ait bilançolarından elde edilen veriler kullanılmıştır. Veriler Finnet veri bankasından temin edilmiştir. Değerlendirme işleminde şirketler sırasıyla; Ak Enerji $\left(A_{1}\right)$, Aksa Enerji $\left(A_{2}\right)$, Aksu Enerji $\left(A_{3}\right)$, Ayen Enerji $\left(A_{4}\right)$, Bomonti Elektrik $\left(A_{5}\right)$,Enerjisa

\begin{tabular}{|c|c|c|}
\hline Oran grubu & Kullanilan Oranlar (Kriterler) & Kullanılış Amacı \\
\hline Büyüme Oranları & $\begin{array}{l}\text { Aktiflerdeki Büyüme }\left(\mathrm{C}_{1}\right) \\
\text { Satsslardaki Büyüme }\left(\mathrm{C}_{2}\right) \\
\text { Özkaynaktaki Büyüme }\left(\mathrm{C}_{3}\right)\end{array}$ & İşletmenin varlıklarındaki büyümeyi gösteren oranlardır \\
\hline Faaliyet Oranları & $\begin{array}{l}\text { Dönen Varlık Devir Hızı }\left(\mathrm{C}_{4}\right) \\
\text { Alacak Devir Hız1 }\left(\mathrm{C}_{5}\right) \\
\text { Aktif Devir Hiz1 }\left(\mathrm{C}_{6}\right) \\
\text { Borç Devir Hız1 }\left(\mathrm{C}_{7}\right)\end{array}$ & $\begin{array}{l}\text { İşletmenin varlıklarının ne derece etkin kullanıldığını } \\
\text { gösteren oranlardır. }\end{array}$ \\
\hline Kaldıraç Oranları & $\begin{array}{l}\text { Toplam Borç / Toplam aktif }\left(\mathrm{C}_{8}\right) \\
\text { Duran Varlık / Devamlı Sermaye }\left(\mathrm{C}_{9}\right)\end{array}$ & $\begin{array}{c}\text { İşletmelerin uzun vadeli yükümlülüklerini yerine getirebilme } \\
\text { yeterliliğini ölçen oranlardır. }\end{array}$ \\
\hline Karlılik Oranları & $\begin{array}{l}\left.\text { Aktif Karlılık (ROA) ( } \mathrm{C}_{10}\right) \\
\text { Özsermaye Karlılığ (ROE) }\left(\mathrm{C}_{11}\right)\end{array}$ & $\begin{array}{l}\text { İşletmenin sahip olduğu varlıkların ne ölçüde verimli } \\
\text { kullanıldığını ölçen oranlardır. }\end{array}$ \\
\hline Likidite Oranları & $\begin{array}{l}\text { Cari Oran }\left(\mathrm{C}_{12}\right) \\
\text { Likit Oran }\left(\mathrm{C}_{13}\right)\end{array}$ & $\begin{array}{c}\text { İşletmenin kıs süreli borçlarını ödeyebilme gücünü ölçen } \\
\text { oranlardır }\end{array}$ \\
\hline
\end{tabular}
Enerji $\left(A_{6}\right)$, Odaş Elektrik $\left(A_{7}\right)$, Zorlu Enerji $\left(A_{8}\right)$ şeklinde belirlenmiştir Değerlendirme kriterleri olarak ise literatürdeki örnekler incelenerek 5 ana 13 alt kriter belirlenmiş olup bu kriterler Tablo 1'de sunulmuştur

Tablo 1. Finansal Performans İcin Değerlendirme Kriterleri

BİST’te işlem gören enerji şirketlerinin finansal performansının sezgisel bulanık mantık ve entropi tabanlı çok kriterli karar verme yöntemi yardımıyla değerlendirilmesi için önerilen yöntem aşağıda belirtilen adımlardan oluşmaktadır. 


\section{Adım: Alternatiflere Ait Verilerin Sözel Olarak Değetlendirilmesi ve Karar Matrisinin Oluşturulmasi}

İlk olarak BİST’te işlem gören 8 enerji şirketinin 2013-2017 dönemine ait veriler Finnet veri bankasından temin edilmiştir. Daha sonra bu verilerin 5 yıllık ortalamaları hesaplanmış ve Tablo 2'de sunulmuştur.

Tablo 2. Alternatiflerin Kriterlere Göre 5 Yullık Ortalama Verileri

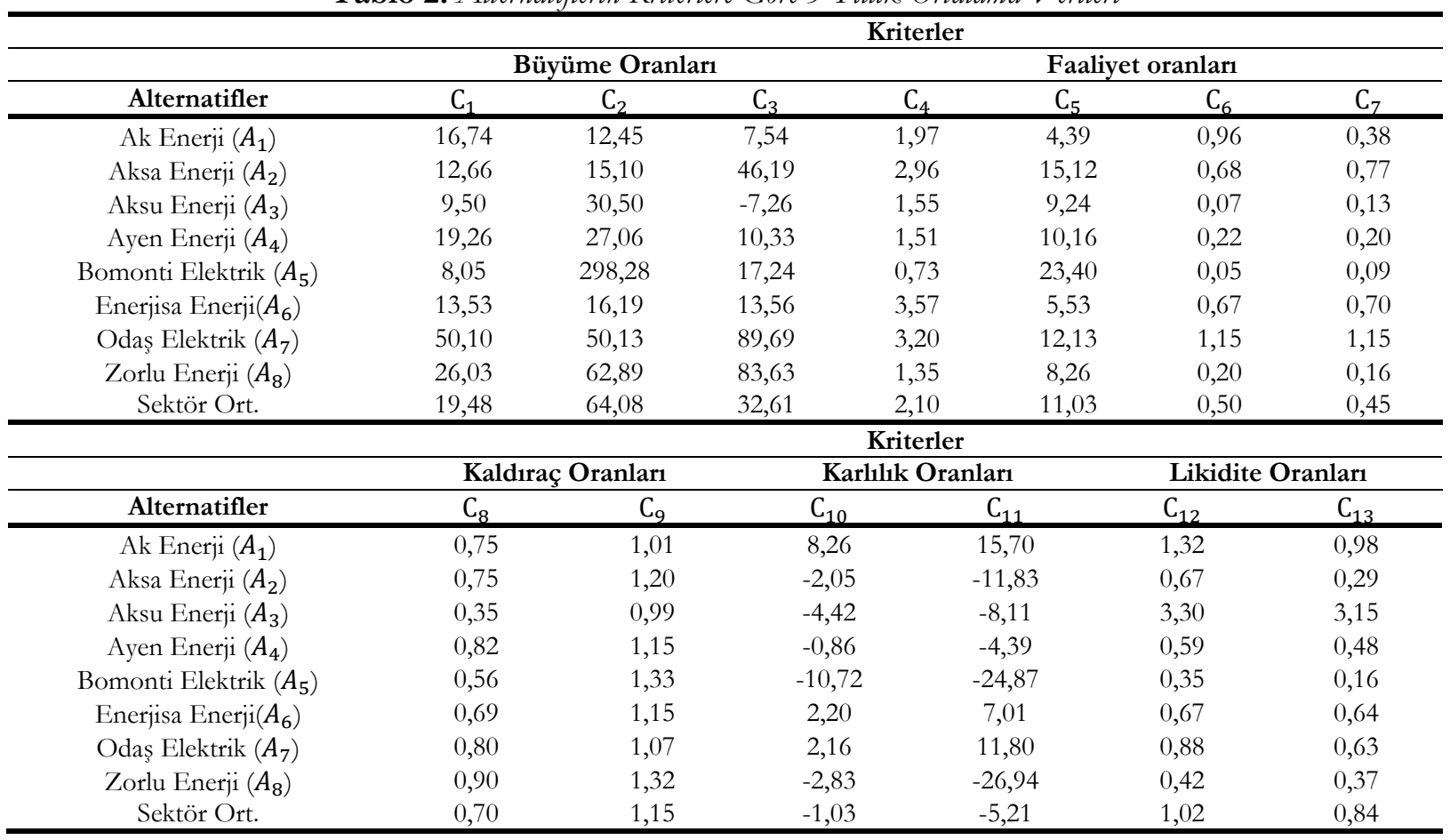

Alternatiflere ait her bir kriter için 5 yıllık ortalamalar hesaplandıktan sonra her bir alternatif, sektör ortalamaları dikkate alınarak dilsel terimler yardımıyla değerlendirilmiştir. Değerlendirme yapılırken daha sağlıklı bir sonuç elde edebilmek için aşırı ve uç değerler değerlendirme dışı bırakılmıştır. Yapılan bu değerlendirme sonucunda her bir dilsel terime karşıllk gelen sezgisel bulanık sayı belirlenmiştir. Her bir dilsel terime karşılık gelen sezgisel bulanık sayılar Efe vd. (2015) çalışmasından elde edilmiştir. Alternatiflerin değerlendirilmesinde kullanılan dilsel terimler ve bu dilsel terimlere karşılık gelen sezgisel bulanık sayılar 'Tablo 3' te sunulmuştur.

Tablo 3. Kriterlerin Değerlendirilmesinde Kullanulan Dilsel Terimler Ve Sezgisel Bulanık Sayı Karşıllkları

\begin{tabular}{cc}
\hline Dilsel Terimler & Sezgisel Bulanık Sayılar \\
\hline Çok iyi (Ç亡) & $(0,90 ; 0,10 ; 0,00)$ \\
İyi (I) & $(0,75 ; 0,20 ; 0,15)$ \\
Orta (O) & $(0,50 ; 0,45 ; 0,05)$ \\
Kötü (K) & $(0,35 ; 0,60 ; 0,05)$ \\
Çok Kötü (ÇK) & $(0,10 ; 0,90 ; 0,00)$ \\
\hline
\end{tabular}

Kaynak: Efe vd. (2015) derlenerek oluşturulmuştur.

Her bir alternatife ait kriterler sektör ortalamaları dikkate alınarak Tablo 3'teki dilsel terimler yardımıyla değerlendirilmiş ve bu değerlendirmelerin dilsel karşılıkları Tablo 4’te sunulmuştur. 
Tablo 4. Alternatiflerin Kriterlere Göre Değerlendirilmesi

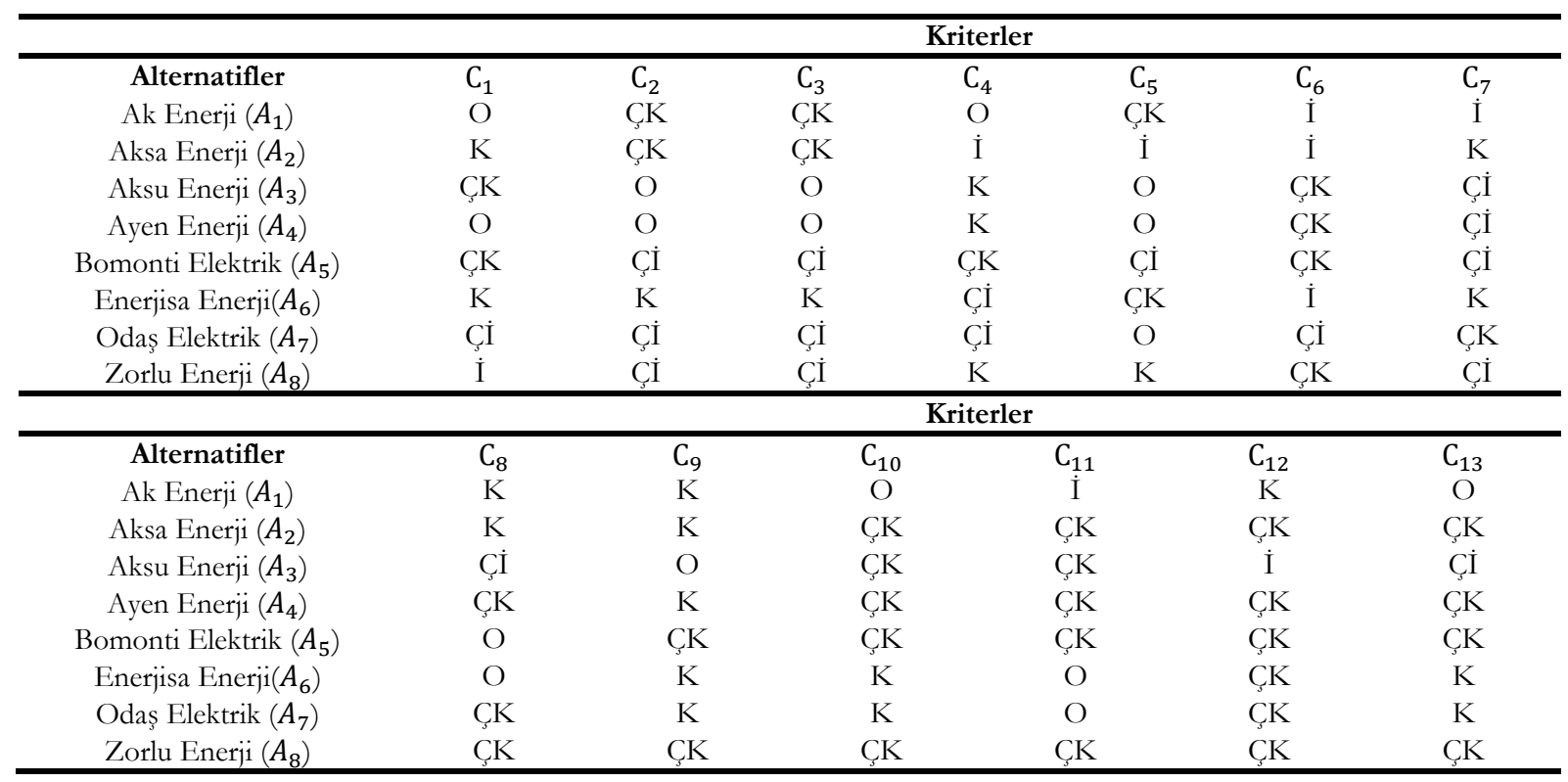

Alternatiflere ait her bir kriter dilsel olarak değerlendirildikten sonra Tablo 4'teki her bir dilsel ifadeye karşılık gelen sezgisel bulanık sayı bulunarak karar matrisi oluşturulmuştur. Oluşturulan karar matrisi Tablo 5’te sunulmuştur.

Tablo 5. Karar Matrisi

\begin{tabular}{|c|c|c|c|c|c|c|c|c|c|c|c|c|c|}
\hline \multicolumn{2}{|c|}{$\mathrm{C}_{1}$} & \multicolumn{2}{|c|}{$\mathrm{C}_{2}$} & \multicolumn{2}{|c|}{$\mathrm{C}_{3}$} & \multicolumn{2}{|c|}{$\mathrm{C}_{4}$} & \multicolumn{2}{|c|}{$\mathrm{C}_{5}$} & \multicolumn{2}{|l|}{$\mathrm{C}_{6}$} & \multicolumn{2}{|c|}{$\mathrm{C}_{7}$} \\
\hline$\mu$ & $\vartheta$ & $\mu$ & $\vartheta$ & $\mu$ & & $\mu$ & $\vartheta$ & $\mu$ & $\vartheta$ & $\mu$ & $\vartheta$ & $\mu$ & $\vartheta$ \\
\hline 0,5 & 0,45 & 0,1 & 0,9 & 0,1 & & 0,5 & 0,45 & 0,9 & 0,1 & 0,75 & 0,2 & 0,75 & 0,2 \\
\hline 0,35 & 0,6 & 0,1 & 0,9 & 0,1 & & 0,75 & 0,2 & 0,75 & 0,2 & 0,75 & 0,2 & 0,35 & 0,6 \\
\hline 0,1 & 0,9 & 0,5 & 0,45 & 0,5 & & 0,35 & 0,6 & 0,5 & 0,45 & 0,1 & 0,9 & 0,9 & 0,1 \\
\hline 0,5 & 0,45 & 0,5 & 0,45 & 0,5 & & 0,35 & 0,6 & 0,5 & 0,45 & 0,1 & 0,9 & 0,9 & 0,1 \\
\hline 0,1 & 0,9 & 0,9 & 0,1 & 0,9 & & 0,1 & 0,9 & 0,9 & 0,1 & 0,1 & 0,9 & 0,9 & 0,1 \\
\hline 0,35 & 0,6 & 0,35 & 0,6 & 0,35 & & 0,9 & 0,1 & 0,1 & 0,9 & 0,75 & 0,2 & 0,35 & 0,6 \\
\hline 0,9 & 0,1 & 0,9 & 0,1 & 0,9 & & 0,9 & 0,1 & 0,5 & 0,45 & 0,9 & 0,1 & 0,1 & 0,9 \\
\hline 0,75 & 0,2 & 0,9 & 0,1 & 0,9 & & 0,35 & 0,6 & 0,35 & 0,6 & 0,1 & 0,9 & 0,9 & 0,1 \\
\hline \multicolumn{2}{|c|}{$\mathrm{C}_{8}$} & \multicolumn{2}{|r|}{$\mathrm{C}_{9}$} & \multicolumn{3}{|c|}{$\mathrm{C}_{10}$} & \multicolumn{2}{|c|}{$\mathrm{C}_{11}$} & \multicolumn{2}{|c|}{$\mathrm{C}_{12}$} & & \multicolumn{2}{|c|}{$\mathrm{C}_{13}$} \\
\hline$\mu$ & $\vartheta$ & $\mu$ & $\vartheta$ & & $\mu$ & $\vartheta$ & $\mu$ & $\vartheta$ & $\mu$ & $\vartheta$ & & $\mu$ & $\vartheta$ \\
\hline 0,35 & 0,6 & 0,35 & 0,6 & & 0,5 & 0,45 & 0,35 & 0,6 & 0,35 & 0,6 & & 0,5 & 0,45 \\
\hline 0,35 & 0,6 & 0,35 & 0,6 & & 0,1 & 0,9 & 0,35 & 0,6 & 0,35 & 0,6 & & 0,1 & 0,9 \\
\hline 0,9 & 0,1 & 0,5 & 0,45 & & 0,1 & 0,9 & 0,9 & 0,1 & 0,5 & 0,45 & & 0,1 & 0,9 \\
\hline 0,1 & 0,9 & 0,35 & 0,6 & & 0,1 & 0,9 & 0,1 & 0,9 & 0,35 & 0,6 & & 0,1 & 0,9 \\
\hline 0,5 & 0,45 & 0,1 & 0,9 & & 0,1 & 0,9 & 0,5 & 0,45 & 0,1 & 0,9 & & 0,1 & 0,9 \\
\hline 0,5 & 0,45 & 0,35 & 0,6 & & 0,35 & 0,6 & 0,5 & 0,45 & 0,35 & 0,6 & & 0,35 & 0,6 \\
\hline 0,1 & 0,9 & 0,35 & 0,6 & & 0,35 & 0,6 & 0,1 & 0,9 & 0,35 & 0,6 & & 0,35 & 0,6 \\
\hline 0,1 & 0,9 & 0,1 & 0,9 & & 0,1 & 0,9 & 0,1 & 0,9 & 0,1 & 0,9 & & 0,1 & 0,9 \\
\hline
\end{tabular}

\section{Adım: Kriter Ağırliklanının Hesaplanması}

Kriter ağırlıklarının hesaplanması için öncelikle Eşitlik (5) yardımıyla Entropy matrisi (E) oluşturulmuştur ve Tablo 6'da sunulmuştur.

$$
\begin{gathered}
e_{11}=1-|0,5-0,45|=0,95 \\
e_{12}=1-|0,1-0,9|=0,2 \\
\vdots \\
e_{8 \times 13}=1-|0,1-0,9|=0,2
\end{gathered}
$$


Tablo 6. Entropy Matrisi

\begin{tabular}{ccccccccccccccccc}
\hline & $\mathrm{C}_{1}$ & $\mathrm{C}_{2}$ & $\mathrm{C}_{3}$ & $\mathrm{C}_{4}$ & $\mathrm{C}_{5}$ & $\mathrm{C}_{6}$ & $\mathrm{C}_{7}$ & $\mathrm{C}_{8}$ & $\mathrm{C}_{9}$ & $\mathrm{C}_{10}$ & $\mathrm{C}_{11}$ & $\mathrm{C}_{12}$ & $\mathrm{C}_{13}$ \\
\hline$A_{1}$ & 0,95 & 0,2 & 0,2 & 0,95 & 0,2 & 0,45 & 0,45 & 0,75 & 0,75 & 0,95 & 0,45 & 0,75 & 0,95 \\
$A_{2}$ & 0,75 & 0,2 & 0,2 & 0,45 & 0,45 & 0,45 & 0,75 & 0,75 & 0,75 & 0,2 & 0,2 & 0,2 & 0,2 \\
$A_{3}$ & 0,2 & 0,95 & 0,95 & 0,75 & 0,95 & 0,2 & 0,2 & 0,2 & 0,95 & 0,2 & 0,2 & 0,45 & 0,2 \\
$A_{4}$ & 0,95 & 0,95 & 0,95 & 0,75 & 0,95 & 0,2 & 0,2 & 0,2 & 0,75 & 0,2 & 0,2 & 0,2 & 0,2 & 0,2 \\
$A_{5}$ & 0,2 & 0,2 & 0,2 & 0,2 & 0,2 & 0,2 & 0,2 & 0,95 & 0,2 & 0,2 & 0,2 & 0,2 & 0,2 & 0,2 \\
$A_{6}$ & 0,75 & 0,75 & 0,75 & 0,2 & 0,2 & 0,45 & 0,75 & 0,95 & 0,75 & 0,75 & 0,95 & 0,2 & 0,75 \\
$A_{7}$ & 0,2 & 0,2 & 0,2 & 0,2 & 0,95 & 0,2 & 0,2 & 0,2 & 0,75 & 0,75 & 0,95 & 0,2 & 0,75 \\
$A_{8}$ & 0,45 & 0,2 & 0,2 & 0,75 & 0,75 & 0,2 & 0,2 & 0,2 & 0,2 & 0,2 & 0,2 & 0,2 & 0,2 \\
\hline
\end{tabular}

Entropy matrisi oluşturulduktan sonra Eşitlik (6) yardımıla Bilgi Tabanlı (K) matris oluşturulmuştur ve Tablo 7 'de sunulmuştur.

$$
\begin{gathered}
K_{11}=1-0,5(0,95+(1-(0,50+0,45))=0,5 \\
K_{12}=1-0,5(0,2+(1-(0,1+0,9))=0,9 \\
\vdots \\
K_{8 * 13}=1-0,5(0,2+(1-(0,1+0,9))=0,9
\end{gathered}
$$

\begin{tabular}{|c|c|c|c|c|c|c|c|c|c|c|c|c|c|}
\hline & $\mathrm{C}_{1}$ & $\mathrm{C}_{2}$ & $\mathrm{C}_{3}$ & $\mathrm{C}_{4}$ & $\mathrm{C}_{5}$ & $\mathrm{C}_{6}$ & $\mathrm{C}_{7}$ & $\mathrm{C}_{8}$ & $\mathrm{C}_{9}$ & $\mathrm{C}_{10}$ & $\mathrm{C}_{11}$ & $\mathrm{C}_{12}$ & $\mathrm{C}_{13}$ \\
\hline$A_{1}$ & 0,5 & 0,9 & 0,9 & 0,5 & 0,9 & 0,75 & 0,75 & 0,6 & 0,6 & 0,5 & 0,75 & 0,6 & 0,5 \\
\hline$A_{2}$ & 0,6 & 0,9 & 0,9 & 0,75 & 0,75 & 0,75 & 0,6 & 0,6 & 0,6 & 0,9 & 0,9 & 0,9 & 0,9 \\
\hline$A_{3}$ & 0,9 & 0,5 & 0,5 & 0,6 & 0,5 & 0,9 & 0,9 & 0,9 & 0,5 & 0,9 & 0,9 & 0,75 & 0,9 \\
\hline$A_{4}$ & 0,5 & 0,5 & 0,5 & 0,6 & 0,5 & 0,9 & 0,9 & 0,9 & 0,6 & 0,9 & 0,9 & 0,9 & 0,9 \\
\hline$A_{5}$ & 0,9 & 0,9 & 0,9 & 0,9 & 0,9 & 0,9 & 0,9 & 0,5 & 0,9 & 0,9 & 0,9 & 0,9 & 0,9 \\
\hline$A_{6}$ & 0,6 & 0,6 & 0,6 & 0,9 & 0,9 & 0,75 & 0,6 & 0,5 & 0,6 & 0,6 & 0,5 & 0,9 & 0,6 \\
\hline$A_{7}$ & 0,9 & 0,9 & 0,9 & 0,9 & 0,5 & 0,9 & 0,9 & 0,9 & 0,6 & 0,6 & 0,5 & 0,9 & 0,6 \\
\hline$A_{8}$ & 0,75 & 0,9 & 0,9 & 0,6 & 0,6 & 0,9 & 0,9 & 0,9 & 0,9 & 0,9 & 0,9 & 0,9 & 0,9 \\
\hline
\end{tabular}

Tablo 7. Bilgi Tabanl Matris

Çok kriterli karar verme problemlerinde her bir kriterin ağırlığı birbirinden farklı olduğu için kriter ağırlıkları $\left(W_{j}\right)$ Eşitlik (7) ve (8) yardımıyla hesaplanmış ve Tablo 8' de sunulmuştur.

$$
\begin{aligned}
& a_{1}=0,5+0,6+0,9+0,5+0,9+0,6+0,9+0,75=5,65 \\
& a_{2}=0,9+0,9+0,5+0,5+0,9+0,6+0,9+0,9=6,1 \\
& \vdots \\
& a_{13}=0,5+0,9+0,9+0,9+0,9+0,6+0,6+0,9=6,2 \\
& a_{T}=a_{1}+a_{2}+\cdots+a_{13}=78,85 \\
& W_{1}=\frac{a_{1}}{a_{T}}=\frac{5,65}{78,85}=0,0716 \\
& W_{2}=\frac{a_{2}}{a_{T}}=\frac{6,1}{78,85}=0,0774 \\
& \quad \vdots \\
& W_{13}=\frac{a_{13}}{a_{T}}=\frac{6,2}{78,85}=0,078
\end{aligned}
$$


Tablo 8. Kriter Ağrrlkklar

\begin{tabular}{|c|c|c|c|}
\hline Ana Kriterler & Alt Kriterler & \multicolumn{2}{|c|}{ Kriter Ağırlıkları } \\
\hline \multirow{3}{*}{ Büyüme Oranlar1 } & Aktiflerdeki Büyüme & 0,0717 & \multirow{3}{*}{0,2265} \\
\hline & Satışlardaki Büyüme & 0,0774 & \\
\hline & Özkaynaktaki Büyüme & 0,0774 & \\
\hline \multirow{4}{*}{ Faaliyet Oranları } & Dönen Varlık Devir Hızı & 0,0729 & \multirow{4}{*}{0,3107} \\
\hline & Alacak Devir Hızı & 0,0704 & \\
\hline & Aktif Devir Hız1 & 0,0856 & \\
\hline & Borç Devir Hızı & 0,0818 & \\
\hline \multirow{2}{*}{ Kaldıraç Oranları } & Toplam Borç / Toplam Aktif & 0,0736 & \multirow{2}{*}{0,1408} \\
\hline & Duran Varlık / Devamlı Sermaye & 0,0672 & \\
\hline \multirow{2}{*}{ Karlılık Oranları } & Aktif Karlılık (ROA) & 0,0786 & \multirow{2}{*}{0,1579} \\
\hline & Özsermaye Karlılı̆̆1 (ROE) & 0,0793 & \\
\hline \multirow{2}{*}{ Likidite Oranları } & Cari Oran & 0,0856 & \multirow{2}{*}{0,1642} \\
\hline & Likit Oran & 0,0786 & \\
\hline
\end{tabular}

\section{Adım: Her Bir Alternatif İçin Ağırlıklandırılmış Ortalama Değerlerin Oluşturulması}

Kriter ağıllıkları bulunduktan sonra her bir alternatif için ağırlıklandırılmış ortalama değerler Eşitlik (9) yardımılla hesaplanmışır ve Tablo 9'da sunulmuştur.

$$
\begin{gathered}
A_{i}=\left(1-\prod_{j=1}^{n}\left(1-\mu_{i j}\right)^{w j}, \quad \prod_{j=1}^{n} \vartheta_{i j}{ }^{w j}=\left(\mu_{i}, \vartheta_{i}\right)\right. \\
A_{1}=1-\left(\left(1-0,5^{0,0717}\right) \times\left(1-0,1^{0,0774}\right) \times \ldots \times\left(1-0,1^{0,0786}\right)\right) ;\left(0,45^{0,0717}\right) \\
\left.\quad \times \ldots \times\left(0,45^{0,0786}\right)\right)=(0,563 ; 0,394) \\
A_{2}=1-\left(\left(1-0,35^{0,0717}\right) \times\left(1-0,1^{0,0774}\right) \times \ldots \times\left(1-0,1^{0,0786}\right)\right) ;\left(\left(0,6^{0,0717}\right)\right. \\
\left.\times \ldots \times\left(0,9^{0,0786}\right)\right)=(0,365 ; 0,593) \\
\quad \vdots \\
A_{8}=1-\left(\left(1-0,75^{0,0717}\right) \times\left(1-0,9^{0,0774}\right) \times \ldots \times\left(1-0,1^{0,0786}\right)\right) ;\left(0,2^{0,0717}\right) \\
\left.\times \ldots \times\left(0,9^{0,0786}\right)\right)=(0,512 ; 0,475)
\end{gathered}
$$

Tablo 9. Alternatiflerin Ağırlkelandırlmış Ortalama Son Değerleri

\begin{tabular}{ccc}
\hline Alternatifler & $\boldsymbol{\mu}$ & $\boldsymbol{\vartheta}$ \\
\hline Ak Enerji $\left(A_{1}\right)$ & 0,563 & 0,394 \\
Aksa Enerji $\left(A_{2}\right)$ & 0,365 & 0,593 \\
Aksu Enerji $\left(A_{3}\right)$ & 0,576 & 0,402 \\
Ayen Enerji $\left(A_{4}\right)$ & 0,363 & 0,611 \\
Bomonti Elektrik $\left(A_{5}\right)$ & 0,536 & 0,46 \\
Enerjisa Enerii $\left(A_{6}\right)$ & 0,453 & 0,509 \\
Odaş Elektrik $\left(A_{7}\right)$ & 0,656 & 0,334 \\
Zorlu Enerji $\left(A_{8}\right)$ & 0,512 & 0,475 \\
\hline
\end{tabular}

\section{Adim Alternatiflerin Siralanmas1}

Her bir alternatif için ağırlıklandırılmış $\mu$ ve $\vartheta$ değerleri hesaplandıktan sonra Eşitlik (10) yardımıyla her bir alternatifin skor fonksiyonu hesaplanmış ve buna göre sıralama yapılmıştır. Alternatiflerin aldığı skorlar Tablo 10'da sunulmuştur.

$$
\begin{aligned}
& \operatorname{Skor}\left(A_{1}\right)=0,563-0,394=0,169 \\
& \operatorname{Skor}\left(A_{2}\right)=0,365-0,593=-0,23
\end{aligned}
$$




\begin{tabular}{|c|c|}
\hline \multicolumn{2}{|c|}{$\operatorname{Skor}\left(A_{8}\right)=0,512-0,475=0,037$} \\
\hline Alternatifler & $\boldsymbol{\mu}-\boldsymbol{\vartheta}$ \\
\hline $\mathrm{Ak}$ Enerji $\left(A_{1}\right)$ & 0,169 \\
\hline Aksa Enerji $\left(A_{2}\right)$ & $-0,23$ \\
\hline Aksu Enerji $\left(A_{3}\right)$ & 0,174 \\
\hline Ayen Enerji $\left(A_{4}\right)$ & $-0,25$ \\
\hline Bomonti Elektrik $\left(A_{5}\right)$ & 0,077 \\
\hline Enerjisa Enerji $\left(A_{6}\right)$ & $-0,06$ \\
\hline Odaş Elektrik $\left(A_{7}\right)$ & 0,322 \\
\hline Zorlu Enerji $\left(A_{8}\right)$ & 0,037 \\
\hline
\end{tabular}

\section{SONUÇ}

Teknolojinin gelişmesi ve küreselleşme süreci şirketlerin faaliyetlerini ve beraberinde üretim süreçlerini geliştirmelerine neden olmuştur. Yeni teknolojiler, yeni ihtiyaçlar ve başkalaşan üretim ilişkileri üretim sürecinde üreticilerin farklı üretim davranışlarına yönelmelerine neden olmuştur. Bu durum ise rekabet seviyesini geliştirmiş, şirketleri farklı arayışlar içerisine itmiştir. Küreselleşen dünyada karlılıklarını artırmak isteyen şirketler artan rekabet düzeyine ayak uydurmak zorundadır.

Rekabet seviyesi şirketlerin davranışlarını, karlılıklarını, üretim seviyelerini ve finansal performanslarını etkilemektedir. Öte yandan gelişen teknolojiyle beraber ülkelerin artan enerji ihtiyacı enerji sektöründe ülkelerin ve haliyle her bir şirketin rekabet seviyelerinin artmasına neden olmuştur. Şirketlerin, artan bu rekabet ortamında ayakta kalabilmek için finansal performanslarını üst düzeyde tutmaları gerekmektedir. Bu noktada şirketlerin finansal performanslarını doğru analiz etmeleri hayati öneme sahiptir. $\mathrm{Bu}$ nedenle şirketlerin finansal performansını analiz etmek için birçok yöntem geliştirilmiştir. Özellikle son yıllarda çok kriterli karar verme yöntemleri finansal performans analizi için sikça kullanılmaktadır.

Bu çalışmada BİST'de işlem gören enerji şirketlerinin finansal performansları sezgisel bulanık mantık ve entropi tabanlı çok kriterli karar verme yöntemiyle analiz edilmiştir. Kriter olarak 5 ana 13 alt kriter kullanılmış olup ana kriterler sırasıyla büyüme, faaliyet, kaldıraç, karlılık ve likidite oranları olarak belirlenmiştir. Her bir alternatif için elde edilen verilerin 5 ylllık ortalamaları sektör ortalamalarıly karşılaştırılarak dilsel olarak değerlendirilmiş ve bu değerlendirme sonucu her bir dilsel terime karşlık gelen sezgisel bulanık sayı değeri bulunarak karar matrisi oluşturulmuştur. Karar matrisi oluşturulduktan sonra her bir kriterin ağırlı̆̆1 hesaplanmış ve bu kriter ağıllıkları kullanılarak her bir alternatifin aldığı skor hesaplanmıştır. Hesaplanan bu skorlara göre alternatifler, en iyi performans gösterenden en kötü performans gösterene doğru sıralanmıştır. Bu doğrultuda yapılan sıralama: $A_{7}$ (Odaş Elektrik) > $A_{3}($ Aksu Enerji $)>A_{1}($ Ak Enerji $)>A_{5}$ (Bomonti Elektrik) $>A_{8}($ Zorlu Enerji $)>$ $A_{6}($ Enerjisa Elektrik $)>A_{2}($ Aksa Elektrik $)>A_{4}$ (Ayen Elektrik) şeklinde elde edilmiştir.

Sonuçlara göre şirketler arasında görece olarak en iyi finansal performansı Odaş Elektrik Üretim Sanayi Ticaret A.Ş. gösterirken görece olarak en kötü performansı Ayen Elektrik Ticaret A.Ş göstermiştir. Şirketlerin finansal performanslarında ortaya çıkan bu sonuçta birçok etmen rol oynamaktadır. Karar verme sürecindeki kriterler bu sonucun oluşmasında aktif rol oynamışır ve bu kriterler şirketlerin gelecekteki faaliyetlerine yol göstermesi açısından önemli bir yere sahiptir. Şirketlerin varlıklarını sürdürmeleri, faaliyetlerini devam ettirebilmeleri açısından karar verme kriterlerini ve göstergelerini iyileştirmeleri hem varlıklarını sürdürmeleri hem de rekabet güçlerini geliştirmeleri adına şirketlere fayda sağlayacaktır.

Yapılan bu çalışmada sezgisel bulanık mantık çok kriterli karar verme teknikleriyle beraber kullanılmıştır. Finans dünyasının belirsizlik içerdiği düşünüldügünde, önerilen bu yöntemin, belirsizlik durumlarında etkin ve kullanışlı bir yöntem olduğu için, hem mevcut duruma farklı bir yönden 1şık tutacağı hem de gelecekte yapılacak çalışmalarda araştırmacılara yol gösterici olarak katkı sağlayacağı umulmaktadır. 


\section{Kaynakça}

Akbulut R. ve Rençber Ö. F. (2015). BİST’te imalat sektöründeki işletmelerin finansal performansları üzerine bir araștırma. Mubasebe ve Finansman Dergisi 65, 117-136.

Atanassovi K. (1986). Intuitionistic fuzzy sets. Fuziy Sets and Systems, 20, 87-96.

Atmaca, M. (2012). İMKB'de işlem gören spor şirketlerinin TOPSIS yöntemi ile finansal performans değerlendirmesi. İktisat, İsletme ve Finans Dergisi, 27(320), 91-108.

Aydın, G. (2009). Marka değeri ve finansal performans. Yayınlanmış Kısaltılmış Doktora Tezi.

Başdeğirmen, A. ve Işıldak B. (2018). Ulaştırma sektöründe faaliyet gösteren işletmelerin performanslarının gri ilişkisel analiz ile değerlendirilmesi. Süleyman Demirel Üniversitesi İktisadi ve İdari Bilimler Fakültesi Dergisi, 23(2), 563-577.

Bo, J. ve Haidong, L. (2008). Research on financial early warning for listed companies based on TOPSIS method. http://www.seidatacollection.com/upload/product/200911/2008jrhy07a17.pdf (02.02.18).

Ceyhan, İ. F. ve Demirci, F. (2017). MULTIMOORA yöntemiyle finansal performans ölçümü: Leasing şirketlerinde bir uygulama. Bartm Üniversitesi İ.I.B.F. Dergisi, 8(15), 277-296.

Chen, S. M. ve J. M. Tan, J. M. (1994). Handling multicriteria fuzzy decisionmaking problems based on vague set theory. Fur:y Sets System, 67, 163-172

Chen, T. Y. ve Li, C. H. (2010). Determining objective weights with intuitionistic fuzzy entropy measures: A comparative analysis. Information, 180, 4207-4222.

Chen, Z. ve Yang, W. (2011). A new multiple attribute group decision making method in intuitionistic fuzzy setting. Appl. Math. Model, 35, 4424-4437.

Das, S., Dutta, B. ve Guha, D. (2014). Weight computation of criteria in a decision making problem by knowledge measure. 2014 International Conference on Soft Computing \& Macbine Intelligence.

Doğan, M. (2013). Katılım ve geleneksel bankaların finansal performanslarının karşılaştırllması: Türkiye örneği. Mubasebe ve Finansman Dergisi, 58, 175-188.

Dumanoğlu, S. ve Ergül, N. (2010). İMKB'de işlem gören teknoloji şirketlerinin mali performans ölçümü. MUFAD Mubasebe ve Finans Dergisi, 48, 101-110.

Ergül, N.(2014). BISST- turizm sektöründeki şirketlerin finansal performans analizi. Cankır Karatekin Üniversitesi İktisadi ve İdari Bilimler Fakuiltesi Dergisi, 4(1), 325-340.

Eyüboğlu, K. ve Çelik, P. (2016). Financial performance evaluation of energy companies with fuzzy AHP an fuzzy TOPSIS methods. Business and Economics Research Journal, 7(3), 21-37.

Karaman, R. (2009). İşletmelerde performans ölçümünün önemi ve modern bir performans ölçme aracı olarak balanced scorecard. Sosyal ve Ekonomike Arastirmalar Dergisi, 16, 411-427.

Kula V., Kandemir T. ve Baykut E. (2016). Borsa İstanbul'da işlem gören sigorta ve BES şirketlerinin finansal performansının gri ilișkisel analiz yöntemi ile incelenmesi. Afyon Kocatepe Üniversitesi İktisadi ve İdari Bilimler Fakiultesi Dergisi, XVIII(1), 37-53.

Orçun, C.. ve Eren B. S. (2017). TOPSIS yöntemi ile finansal performans değerlendirmesi: XUTEK üzerinde bir uygulama. Muhasebe ve Finansman Dergisi, 75, 139-154

Shaverdi, M., Ramezani, I., Tahmasebi, R. ve Rostamy, A. A. A. (2016). Combining fuzzy AHP and fuzzy TOPSIS with financial ratios to design a novel performance evaluation model. International Journal of Fuzisy Systems, 18(2), $248-262$.

Tezergil, S. A (2016). Vikor yöntemi ile Türk bankacıllk sektörünün performans analizi. Marmara Üniversitesi İktisadi ve İdari Bilimler Dergisi 38(1), 357-373

Wang, T. C. ve Hsu, J. C. (2004). Evaluation of the business operation performance of the listing companies by applying TOPSIS METHOD. IEEE International Conference on Systems, Man and Cybernestics, 2, 1286-1291.

Xu, Z. (2007). Intuitionistic fuzzy aggregation operators. IEEE Transactions on Fuziy Systems, 15, 1179-1187.

Yıldırım, M., Altan, İ. M. ve Gemici, R. (2018). Kurumsal yönetim ile finansal performans arasındaki ilişkinin entropi ağırlıklandırmalı topsis yöntemi ile değerlendirilmesi: BİST’te İşlem Gören Gıda ve İçecek Şirketlerinde Bir Araştırma. Muhasebe ve Vergi Uygulamalar Dergisi, 11(2), 130-152.

Yıldız, Ş ve Kişoğlu, S. (2011). Bulanık mantık yaklaşımı ile hazır giyimde beden numarası belirleme. e-Journal of New World Sciences Academy, 6(1), 12-22.

Zadeh, L. A. (1965). Fuzzy sets. Information and Control, 8(3), 338-350.

\section{EXTENDED ABSTRACT}

Disappearance of the boundaries along with the process of globalization, has led companies to face fierce competition conditions. Companies that can adapt to these competitive conditions can survive. Companies that cannot adapt to those conditions will lose their market shares and profitability and afterwards their existence. At this point, companies should constantly renew themselves and keep their performance at a high level in order to sustain their beings. Companies that can keep their financial performance at a high level could have a competitive advantage in national and international markets. 
Companies which have a competitive advantage increase their profitability and market share. This naturally enables of the company t successful and maintain its existence.

Maintaining their existence is a very important process for companies and there are many factors in order to sustain this process. One of the most important factors for companies to maintain their existence is to measure, analyze and interpret their financial performance in the most accurate way.

The financial performances of the enterprises are calculated by alternative methods in order to view the targeted and reached situation. These calculations require taking many criteria into consideration and evaluating it accordingly. For this purpose, it is quite common to use multi-criteria decision-making methods in performance analyzes, which allow evaluation based on different criteria.

The most important step is to determine the weight of criteria in multi-criteria decision-making problems. Criteria-weighting is the most faced problem by the researchers. For this reason several ways have been developed in order to use in criteria-weighting. Equal weighting, entropy-based weighting and weighting with the help of expert opinion are some of these methods.

The universe we live in is full of uncertain, inconsistent and incomplete information. It is not easy to process this complex information by classic methods. For this reason, Zadeh (1965) described the theory of fuzzy sets in order to express these complex and ambiguous situations in real life.

Zadeh (1965) stated that fuzzy logic reflects human mental working processes more accurately than classical logic in uncertainty situations. The success of fuzzy logic in modeling uncertain situations and its predisposition of human thought and decision making enable to use of fuzzy logic in finance. Especially in recent years, multi-criteria decision-making methods interbedded with fuzzy logic have begun to be widely used in decision making problems such as choosing the best among alternatives, sorting alternatives together. Although the use of fuzzy logic in the finance field is quite new, the number of studies is increasing day by day. In this study, an entropy-based multi-criteria decision making method was developed by using intuitionistic fuzzy sets (Atanassov, 1986), a generalization of the fuzzy sets of Zadeh.

In this study, 13 financial ratios were calculated by using the related financial statements of 8 energy companies traded in Borsa Istanbul (BIST) between the years of 2013-2017. These financial ratios constitute the criteria used in the study. Criteria consist of 5 main criteria which are namely growth, activity, leverage, profitability, liquidity and consist 13 sub-criteria.

Each alternative was evaluated with the help of linguistic terms by considering the sector averages after calculating the 5-year averages for each criterion of the alternatives. Extreme values were neglected in evaluating process in order to have healthier results. As a result of this evaluation, the intuitionistic fuzzy number corresponding to each linguistic term was determined and a decision matrix was formed accordingly.

Criteria weights were calculated because the weight of each criterion was different in the multicriteria decision-making problems. When calculating the weight of the criteria, an entropy matrix was created with the help of the decision matrix that was created before and then an information based matrix was created with the help of this entropy matrix. After the information-based matrix was created, the weights of each criterion were calculated. After calculating the weight of the criteria, the weighted mean values for each alternative were calculated. For each alternative, after calculating the weighted mean values, the score function of each alternative was calculated. According to these calculated scores, the alternatives were ranked from the best performing to the worst performing. Ranking become: $A_{7}$ (OdaşElektrik) $>A_{3}($ Aksu Enerji $)>A_{1}($ Ak Enerji $)>A_{5}$ (Bomonti Elektrik) $>$ $A_{8}($ Zorlu Enerji $)>\quad A_{6}($ Enerjisa Elektrik $)>\quad A_{2}($ Aksa Elektrik $)>A_{4}($ Ayen Elektrik $)$. According to the results relatively best performing company among the others was Odaş Elektrik Uretim Sanayi Ticaret A.Ş. and the relatively worst was Ayen Elektrik Ticaret A.Ş. Various factors play a role in the financial performance of companies.

Criteria in the decision-making process have played an active role on the result and these criteria have important effect to guide the future activities of companies. It is important for companies to improve their decision making criteria in order to be more competitive and also survive. When measuring performance, it is very important to determine the criteria correctly and to accurately weight those criteria. Incorrectly determined and incorrectly weighted criteria may prevent reaching correct results. Therefore, when determining criteria and weighting, previous studies should be carefully examined and decided 
KARCIOĞLU, YALÇIN ve GÜLTEKIN

Seagisel Bulanık. Mantık ve Entropi Tabanl Çok Kriterli Karar Verme Yöntemiyle Finansal Performans Analizi: BİST'de Ișslem Gören Enerji Şirketleri Üzerine Bir Uygulama

accordingly. In this study, intuitionistic fuzzy logic is used with multi-criteria decision making techniques. Considering the uncertainty of the financial world, it is hoped that this proposed method will be effective and useful in uncertainty situations and will enlighten the current situation in a different way and also contribute to the future research 